\title{
Inhibition of estrogen receptor signaling
}

\author{
E. M. Rosen, S. Fan \\ Department of Oncology, Lombardi Cancer Center, Georgetown University, Washington, DC, USA.
}

\begin{abstract}
The estrogen receptor-alpha (ER- $\alpha$ ) is a Type I nuclear receptor that is over-expressed in the majority of human breast cancers and plays a significant role in the development and progression of these cancers. As estrogen plays important roles in the etiology of breast cancer and the growth of established ER- $\alpha$ expressing cancers, intense interest has been generated in understanding the mechanisms by which ER- $\alpha$ signaling is regulated physiologically and using this knowledge to develop interventions to inhibit ER- $\alpha$ signaling. These efforts have met with some success in the development of pharmacologic agents that can reduce breast cancer risk, prevent recurrence of established cancers, and treat advanced cancers with considerably less side effects than cytotoxic chemotherapy. Here, we will review some of the mechanisms that operate to inhibit $E R-\alpha$ signaling and describe how pharmacologic agents and dietary factors interact with ER- $\alpha$ to block its activity. In the process of reviewing these mechanisms, we will highlight their clinical implications.
\end{abstract}

Keywords: Breast cancer susceptibility gene 1 (BRCA1); Estrogen receptor; ER- $\alpha$; ER- $\beta$; Signaling; Repression; SERMs

\section{Introduction}

Estrogen receptor-alpha (ER- $\alpha$ ) is a member of the nuclear receptor (NR) family of ligand-activatable transcription factors. It is classified as a Type I NR, along with other steroid hormone receptors, including the progesterone receptor (PR), and androgen receptor (AR). When activated by their specific ligands, Type I receptors bind as homodimers to specific hormone response elements that are inverted halfsites: estrogen response elements (EREs), progesterone response elements (PREs), and androgen response elements (AREs). Type II receptors (e.g. thyroid receptor and retinoic acid receptors (RARs)) are usually localized in the nucleus even in the absence of ligands; and following ligation, they bind to their specific response elements as heterodimers

Correspondence to: Dr. Eliot M. Rosen, MD, PhD, Department of Oncology, Lombardi Cancer Center, Georgetown University, 3970 Reservoir Road, NW, Box 571469, Washington, DC 20057-1469, USA. E-mail: emr36@georgetown.edu; Tel: +1 202687 7695; Fax: +1202 6877256

Publication date 31/03/05

BCO/317/2004/FO with the retinoid $X$ receptor (RXR, the 9-cis-RAR). Type III receptors (also called orphan NRs) have domain structures similar to other NRs but have no known ligands.

A second receptor with a high degree of homology to ER- $\alpha$ was discovered nearly a decade ago [1]. This receptor, called ER- $\beta$, has an overlapping but distinct set of functions and a different tissue distribution. A set of estrogen-related receptors (ERR- $\alpha$, ERR- $\beta$, and ERR- $\gamma$ ) has also been identified [2]. The ERRs (also called ESRRA, ESRRB, and ESRRG, respectively with the above) are considered to be orphan NRs since high-affinity ligands have not been identified. Their physiologic functions are unclear, although they may play roles in normal development. This review will focus on ER- $\alpha$, which is the major estrogen receptor (ER) in mammary tissue and which has been linked to the development and progression of human breast cancer. To understand how ER- $\alpha$ signaling can be inhibited, it is first necessary to understand a little about its basic structure and mechanism of activation.

Like other NRs, ER- $\alpha$ has a modular structure, consisting of six domains designated alphabetically 
$(A-F)$. The $A$ and $B$ domains located at the aminoterminus of the ER- $\alpha$ protein contain a transcriptional activation function (AF-1) that does not require a ligand for activity and is constitutively active when linked to a suitable DNA-binding domain (DBD) [3]. The $\mathrm{C}$ domain contains the DBD, which contains two zinc fingers, structures that specifically recognize the ERE [4]. The D domain contains a flexible hinge domain; while the $\mathrm{E}$ domain contains the ligandbinding domain (LBD) and a second transcriptional activation domain that requires ligand for activation (AF-2). The carboxylterminal $\mathrm{F}$ domain contributes to the ligand-binding pocket when the receptor is activated and also to the binding of coactivators such as steroid receptor coactivator-1 (SRC-1) [5]. Maximal activation of ER- $\alpha$ requires an interaction between the two activation domains AF-1 and AF-2, which occurs when the ligand and coactivator proteins are present [6].

A classical scheme for ER- $\alpha$ activation involves a series of events. In this scheme, ligation of cytoplasmic ER- $\alpha$ with $17 \beta$-estradiol (E2) induces a conformational change in the receptor that causes:

1. release of heat shock proteins (HSPs, chaperones that maintain ER- $\alpha$ in an inactive but activatable configuration);

2. translocation of ER- $\alpha$ to the nucleus;

3. homodimerization;

4. binding of the dimer to two ERE half-sites within the regulatory regions of target genes;

5. formation of a coactivator complex;

6. recruitment of the basal transcription factor (BTF).

(Note: Not necessarily in that exact order.) ER- $\alpha$ mediated stimulation of expression of expression of target genes is a complex process that also involves:

1. post-translational modification of histones (methylation and acetylation) to convert the local chromatin structure to a permissive state for transcription;

2. ATP-dependent remodeling of chromatin by the SWI/SNF chromatin remodeling complex;

3. recruitment of a 'mediator' (TRAP/DRIP) complex that makes stimulatory contacts with the BTF.

The main topic of this review is the mechanisms by which ER- $\alpha$ signaling may be inhibited, with particular emphasis on mechanisms that may be relevant to the etiology of breast cancer, its prevention, and its treatment. We include here a discussion of corepressors (coregulatory proteins that bind and inhibit ER- $\alpha$ and other NRs); the tumor suppressor BRCA1; anti-estrogens (selective estrogen receptor modulators (SERMs) that have found usage in breast cancer treatment and prevention); modification of estrogen production (by aromatase inhibitors); ER- $\beta$ (which can oppose the action of ER- $\alpha$ ); epigenetic silencing; and dietary factors that can inhibit ER- $\alpha$ by different mechanisms. This list is not complete. For example, ER- $\alpha$ signaling can be blocked by downregulation of its expression or its targeting for destruction in proteasomes [7]. However, it includes the mechanisms generally considered to be the most relevant to breast cancer treatment and prevention.

\section{Inhibition of ER- $\alpha$ signaling}

\section{Corepressors}

Transcriptional inhibition is now known to be an active process, mediated by high molecular weight multiprotein complexes that include transcriptional repressors, corepressors, histone deacetylases (HDACs) and a variety of auxiliary proteins (e.g. the Mi-2/NuRD complex, mSin3/HDAC1/2- and NCoR (nuclear receptor corepressor)/SMRT (silencing mediator of retinoid and thyroid receptors)/HDAC3containing complexes) [8]. The role of corepressor proteins in negatively regulating $\mathrm{ER}-\alpha$ signaling has been reviewed elsewhere in depth [9]. Here, we will highlight a few mechanisms through which different corepressors may block ER- $\alpha$ signaling. Transcriptional coregulators are auxiliary proteins that can either increase (coactivators) or decrease (corepressors) the rate of transcription of target genes for NRs such as ER- $\alpha$. In some cases, the same coregulator can stimulate or inhibit transcription in different contexts.

The idea of ER- $\alpha$ corepressors has been somewhat controversial until recently, because it is in conflict with the classical scheme for ER- $\alpha$ activation described above, in which the unliganded ER- $\alpha$ is held in an inactive configuration in the cytoplasm complexes with chaperones (e.g. HSP9O $\alpha$ and cochaperone p23) [10]. In the corepressor model, $E R-\alpha$ is localized in the nucleus, bound to DNA of target genes. However, it is transcriptionally inactive because it is associated with a corepressor complex, which converts the local chromatin structure into a repressive state. Over 20 different corepressors for $E R-\alpha$ have been identified [9]. These proteins bind to different portions of ER- $\alpha$ (e.g. AF-1, the DBD, and the AF-2/LBD region) and mediate repression by different mechanisms. For example, some corepressors act by recruiting HDACs (e.g. NCoR and SMRT); while other mediate HDAC-independent repression (e.g. RTA (repressor of Tamoxifen transcriptional activity) and LCoR (ligand-dependent corepressor)). Others act by competition with ER- $\alpha$ coactivators (e.g. REA (repressor of estrogen receptor activity) and SHARP (SMART/HDAC1-associated repressor protein)), 
interference with ER- $\alpha$ DNA binding (e.g. SHP (small heterodimer partner) and COUP-TF (chicken ovalbumin upstream promoter-transcription factor)), inhibition of ER- $\alpha$ dimerization (DAX-1 (DSS-AHC critical region on the $X$ chromosome, gene 1 ) and TR2 (testisderived orphan NR)), and/or sequestering ER- $\alpha$ in the cytoplasm (MTA1s, metastatic tumor-associated 1). A number of these corepressors work through more than one mechanism. Several of the above 'corepressors' are actually Type III (orphan) NRs, a number of which function, in part, to regulate the activity of Type I and Type II NRs (SHP, COUP-TF, DAX-1, and TR2).

An advance in the understanding of how NR coregulators work was the identification of helical motifs that mediate stimulator interactions with NRs (the 'LxxLL' motif (NR box)) or that mediate inhibitory interactions (the '(L/I)XX(I/V)l' motif (CoRNR box) or the ' $\operatorname{Lxx}(1 / \mathrm{H}) \mid \operatorname{xxx}(\mathrm{I} / \mathrm{L})$ ' motif (extended helix motif)) [11-13]. Many coactivators contain one or more NR boxes (e.g. SRC-1, GRIP1, p300/CBP); while many corepressors contain CoRNR or extended helix motifs (e.g. NCoR and SMRT). The stimulatory and inhibitory motifs yield different helical configurations when they interact with NRs, such as ER- $\alpha$. As noted below, the binding of some ligands (e.g. Tamoxifen) confers a three-dimensional conformation of ER- $\alpha$ that promotes the binding of corepressors rather than coactivators. Although many different corepressors clearly inhibit ER- $\alpha$ signaling in cell culture experiments, a lot less is known about the function of these molecules in vivo and, in particular, their roles in breast cancer development and progression.

\section{BRCA1}

The breast cancer susceptibility gene 1 (BRCA1) is a tumor suppressor gene, mutations of which are linked to hereditary early-onset breast cancer and breast/ ovarian cancer syndromes [14]. A body of evidence suggests that BRCA1 may function, in part, as a caretaker gene to protect the integrity of the genome [15]. However, this generic function does not explain why BRCA1 mutations are linked to development of specific cancer types, and particularly to estrogenresponsive cancers (breast, endometrial, and cervical cancers) [16]. A molecular linkage between BRCA1 and ER- $\alpha$ was demonstrated by the finding that BRCA1 over-expression inhibits signaling by the liganded ER- $\alpha$ through the classical ERE in cultured cells [17]. This and subsequent studies revealed that BRCA1 blocks the activity of the intact ER- $\alpha$ and the E2-activated AF-2/LBD but has no effect on the activity of the E2-independent AF-1 domain [18]. BRCA1 also blocked the E2-stimulated expression of two estrogen-responsive genes, pS2 and cathepsin D [19].
Several potential mechanisms for BRCA1 inhibition of ER- $\alpha$ have been identified: (1) a physical interaction between the BRCA1 and ER- $\alpha$ proteins, which occurs independently of E2; and 2) downregulation of expression of p300, an NR coactivator $[18,19]$. The BRCA1:ER- $\alpha$ interaction was mapped to the aminoterminus of BRCA1 and a helical region within the AF-2 domain of ER- $\alpha$ [20]. The relevance of this mechanism to breast cancer was suggested by the finding that various cancer-associated BRCA1 mutant proteins failed to or showed reduced ability to inhibit ER- $\alpha$ activity $[19,20]$. Over-expression of p300 or its functional homolog CBP (the CREB-binding protein) rescued the BRCA1 inhibition of ER- $\alpha$ [18]. Interestingly, the ability of p300/CBP to rescue the inhibition of ER- $\alpha$ mapped to a conserved cysteine-histidine rich region $\left(\mathrm{CH}_{3}\right)$, that was necessary and sufficient for rescue [18]. This finding suggests that the rescue function is distinct from the ability of p300/CBP to coactivate ER- $\alpha$, since the histone acetyltransferase (HAT) and SRC-1-binding domains were dispensable for rescue. A further indication that coactivation and derepression are distinct mechanisms is the finding that GRIP1 (glucocorticoid receptor interacting protein-1) and PCAF (p300/CBP-associated factor) failed to rescue the BRCA1 inhibition of ER- $\alpha$.

A higher resolution analysis of the BRCA1:ER- $\alpha$ interaction revealed two potential contact sites for BRCA1 on ER- $\alpha$ (the major site in a helical region within amino acids 338-379) and two contact sites for ER- $\alpha$ on BRCA1 (the major site containing a conserved helical motif (amino acids 86-95) resembling a previously identified nuclear corepressor motif $(\operatorname{Lxx}(1 / H) \mid \mathrm{xxx}(1 / L)$, where $x=$ any amino acid) [20]. Based on a computer-generated model, BRCA1 heterodimerizes with ER- $\alpha$ via the anti-parallel $\alpha$-helix domain, mainly using the third helix (amino acids 80-96) of BRCA1. The ER- $\alpha$ side of the interface is an $\alpha$-helix of ER- $\alpha$ (amino acids 338-379), which is at the opposite side of the ER- $\alpha$ homodimerization interface. Two tumor-associated BRCA1 mutations at the BRCA1: ER- $\alpha$ interface (L63F and I89T) impaired the ability of BRCA1 to inhibit ER- $\alpha$ activity [20].

Several studies suggest that in addition to inhibiting E2-stimulated ER- $\alpha$ activity, BRCA1 also mediates ligand-independent repression of ER- $\alpha$ activity. Thus, ER- $\alpha$ was found to be constitutively active in the absence of ligand in cells harboring a homozygous null mutation of BRCA1; and BRCA1 was present at the ERE site on the promoter of the E2-responsive gene cathepsin D in MCF-7 human breast cancer cells before but not after stimulation with E2 [21]. Consistent with these findings, knockdown of endogenous BRCA1 by RNA interference conferred ligand-independent activation of ER- $\alpha$ in MCF-7 
cells [21]. Furthermore, BRCA1 knockdown enhanced the degree of E2-stimulated ER- $\alpha$ activity, with a higher fold-stimulation of ER- $\alpha$ activity at lower doses of E2. Thus, the absence or inactivation of BRCA1 may promote ER- $\alpha$ activity under physiologic conditions of low or zero E2.

Recent studies have identified a pool of ER- $\alpha$ at the plasma membrane [22]. The membrane-localized ER- $\alpha$ is G-protein coupled and mediates signaling through cross-talk with the epidermal growth factor receptor (EGFR) or insulin-like growth factor-1 receptor (IGF1R) [22]. In several E2-responsive breast cancer cell lines, E2 caused activation of extracellular signal-related kinase (ERK) signaling that was blocked by wild type but not mutant BRCA1 [23]. BRCA1blocked EGF-induced ERK activation and cell proliferation through a mechanism involving an ERK phosphatase [23]. Thus, BRCA1 may inhibit E2stimulated cell proliferation by blocking cross-talk with the EGFR.

\section{SERMs}

Anti-estrogen therapy has been a mainstay in the treatment of hormone-responsive breast for over 20 years [24]. Tamoxifen, a SERM, has been the agent of choice for hormone-responsive cancers in postmenopausal women. SERMs have mixed ER- $\alpha$ antagonist/agonist activity in different tissues. Thus, Tamoxifen acts as an ER- $\alpha$ antagonist in the breast (hence its use in breast cancer) but functions as an ER- $\alpha$ agonist in bone, the cardiovascular system, and the uterus [25]. Manifestations of its agonistic activity include beneficial actions (potential reduction in osteoporosis and fractures) and harmful actions (increase in the incidence of endometrial carcinoma). Tamoxifen efficacy has been demonstrated as an adjuvant treatment for post-menopausal hormone receptor-positive breast cancer and, more recently, as a chemoprevention agent for younger women at high risk for the development of breast cancer [26]. Recent studies indicate that Tamoxifen binding to ER- $\alpha$ causes it to adopt a configuration that is different from that induced by E2 [27]. This configurational change not only inhibits the ability of ER- $\alpha$ to recruit coactivators but also enhances the recruitment of corepressors. Thus, the presence of Tamoxifen enhances the binding of NCoR, SMRT, REA, RTA, and other corepressors to ER- $\alpha$; and over-expression of some corepressors enhance the antagonist activity of Tamoxifen, while under-expression of corepressors stimulate Tamoxifen's agonist activity [28].

Thus, one explanation for the ability of Tamoxifen to act as an antagonist vs. agonist in different tissues is tissue-specific differences in the balance of corepressors vs. coactivators. Because AF-1 can function autonomously as a ligand-independent transcriptional activation domain, it has been suggested that conditions that enhance AF-1 activity promote Tamoxifen's agonist activity, as observed in endometrial cells [29-31]. Various factors that may contribute to increased AF-1 activity have been identified, including [31-38]:

1. differential effects of different anti-estrogens upon AF-1 activation (Tamoxifen allows greater AF-1 activation than Raloxifene, a SERM that does not increase the risk of endometrial carcinoma);

2. differential effects of anti-estrogens in allowing the recruitment of corepressors and HDACs;

3. signal transduction pathways that promote activation of AF-1 (e.g. MAP kinase mediated phosphorylation of serine-118 and c-Akt mediated phosphorylation of serine-167, both within the AF-1 domain of ER- $\alpha$ );

4. increased ER- $\alpha$ expression and promoter occupancy.

These mechanisms may contribute to both the agonist activity of Tamoxifen in the uterus and the development of Tamoxifen resistance in breast cancer.

Other anti-estrogens include Raloxifene (Evista, a second generation SERM) and ICI 182,780 (Faslodex). Raloxifene exerts anti-estrogenic activity in the breast and uterus and pro-estrogenic activity in bone and in the cardiovascular system [39]. The Multiple Outcomes of Raloxifene Evaluation (MORE) trial was originally designed to test the ability of Raloxifene to reduce the incidence of osteoporosis and fractures in older women. Although the women in this trial were not specifically at increased risk for breast cancer, this trial showed a significant risk reduction for breast cancer, without a concomitant increase in the risk for endometrial cancer [40-42]. In both the MORE trial and the NSABP-P1 breast cancer prevention [26], Raloxifene and Tamoxifen, respectively, effectively prevented the development of ER-positive breast cancers but not ER-negative cancers. These findings suggest a difference in the cell of origin for ER- $\alpha(+)$ vs. ER- $\alpha(-)$ cancers or the conversion of ER- $\alpha(+)$ to ER- $\alpha(-)$ status during the pathogenesis of Tamoxifen-resistant ER- $\alpha(-)$ cancers. Faslodex (also called Fulvestrant) is a pure anti-estrogen that inhibits both AF-1 and AF-2 activity, promotes the degradation of $E R-\alpha$, and, as far as we know, acts as an ER- $\alpha$ antagonist in all estrogen-responsive tissues (e.g. breast, bone, cardiovascular, and uterus) [43-45]. Its major use has been in treatment of advanced ER- $\alpha(+)$ breast cancers, particularly in the treatment of Tamoxifen-resistant cancers $[45,46]$. Interestingly, ICI 182,780 requires a specific ER- $\alpha$ corepressor (NEDD8, neural precursor cell 
expressed developmental downregulated 8) to exert its anti-estrogenic activity. Thus, inhibition of the NEDD8 pathway conferred cellular resistance to ICI 182,780 [44].

\section{Modification of estrogen production}

A recent advance in the treatment of estrogenresponsive breast cancer is the development of aromatase inhibitors. The clinical aspects of aromatase inhibitors have been reviewed elsewhere [47-49]. The enzyme aromatase (also called CYP19 or CYP19A1) is a member of the cytochrome P450 superfamily of microsomal monoxygenases that mediate the metabolism of drugs and xenobiotics, synthesis of cholesterol, and synthesis of steroids and other lipids [50]. Aromatase is localized in the endoplasmic reticulum and mediates the conversion of androgens into estrogen. In post-menopausal women, the major source of estrogen is the peripheral conversion of adrenal androgens into estrogen, which occurs in fat and other tissues [51]. Third generation aromatase inhibitors that have been tested in clinical trials include anastrazole (Arimidex), letrazole (Femara), and exemestane (Aromasin). These trials suggest that aromatase inhibitors are at least as effective as or more effective than Tamoxifen in reducing the risk of recurrence or new breast cancers in post-menopausal women with ER-positive tumors when used in an adjuvant setting [47]. A potential advantage of aromatase inhibitors is that unlike Tamoxifen, which acts as ER agonist in the uterus, aromatase inhibitors do not have pro-estrogenic effects and do not appear to increase the risk of endometrial cancer. A disadvantage is that aromatase inhibitors may increase the risk of osteoporosis and fractures because of the reduction of circulating estrogens. In contrast, Tamoxifen acts as an ER agonist in bone and does not increase the risk of fractures. Anastrazole has been approved by the Food and Drug Administration (FDA) for use as adjuvant treatment for breast cancer in post-menopausal women and appears to be a reasonable alternative to Tamoxifen.

\section{Estrogen receptor- $\beta$}

ER- $\beta$ (also called ESR2, or estrogen receptor 2 ) is structurally similar to ER- $\beta$, particularly within the DBD, but exhibits a different tissue distribution and overlapping but distinct functional properties with respect to ligand selectivity, binding affinity, and transcriptional activation [1]. ER- $\beta$ is highly expressed in the ovary, testis, prostate spleen, and thymus; but it is also found in other tissues, including the uterus and the breast $[1,52]$. In ER- $\beta$ knockout (BERKO) mice, E2 caused an exaggerated proliferative and biochemical response in the uterus, suggesting that ER- $\beta$ negatively regulates ER- $\alpha$ signaling [53]. In response to E2, ER- $\beta$ may form heterodimers with $E R-\alpha$, suggesting that heterodimerization with ER- $\beta$ may modulate the function of ER- $\alpha[54,55]$. In a study of ER- $\alpha$ or ER- $\beta$ mediated signaling, co-expression of ER- $\alpha$ and ER- $\beta$ caused reduced E2-stimulated transcription at low concentrations of E2 [55]. Similar findings were reported in an earlier study in which it was also observed that in contrast to ER- $\alpha$, the ER- $\beta$ AF- 1 was a weak activator domain that actually reduced the transcriptional activity of the intact ER- $\beta$ [55]. Co-expression of ER- $\alpha$ and ER- $\beta$ not only resulted in a reduced sensitivity to $E 2$, but also caused a reduction of the agonist activity and an increase in the antagonist activity of Tamoxifen [55-57]. These findings further support the idea that AF-1 may mediate the agonistic activity of Tamoxifen.

The vascular endothelial growth factor (VEGF) gene promoter contains an ERE and is E2 responsive. Interestingly, in human breast cancer cells expressing ER- $\alpha$ or ER- $\beta$ alone, E2-stimulated VEGF transcription, while E2 inhibited VEGF transcription in cells expressing both ERs, suggesting that the heterodimer mediates an inhibitory signal [56]. While most studies suggest an antagonistic relationship between ER- $\alpha$ and ER- $\beta$ when both are present in the form of a heterodimer, one recent study has challenged this view [58]. Here, it was reported that a genetic fusion of $E R-\alpha$, with ER- $\beta$ to form a single-chain ER, the heterofusion ER mimicked the properties of $E R-\alpha$ rather than ER- $\beta$, as suggested by the co-expression studies. The story is even further complicated by the finding that both ER- $\alpha$ and ER- $\beta$ have naturally occurring splice variants that can modulate the activity of the full-length receptors [59]. Further studies will be required to determine the physiologic significance of ER- $\alpha$ /ER- $\beta$ interactions in vivo and their relevance to breast cancer.

\section{Epigenetic silencing of ER- $\alpha$}

Silencing of expression of subsets of genes occurs as a consequence of normal development (e.g. imprinting), aging and neoplasia and may contribute to these processes [60-62]. Expression of DNA (cytosine-5)-methyltransferase 1 (DNMT1) is called a 'maintenance DNA methyltransferase', because it methylates newly replicated DNA that is hemimethylated, thus maintaining the pre-replication methylation status [63]. DNMT3a and DNMT3b are classified as de novo methyltransferases, because they can methylate previously unmethylated DNA [64]. DNA methyltransferases may work in conjunction with HDACs and other repressors to maintain chromatin in a transcriptionally silent state. This mechanism is 
suggested by the observation that the methyl CpGbinding protein MeCP2 can recruit a multiprotein repressor complex containing the transcriptional repressor mSin3A, HDAC1, and HDAC2 [65]. DNA methyltransferases have also been shown to be present in repressor complexes containing HDACs and non-HDAC transcriptional repressor proteins $[66,67]$. DNA methyltransferase activity appears to be low in normal human cells, but DNMT1, DNMT3a, and DNMT3b may be over-expressed, with concomitant increases in DNMT activity in a variety of cancer types [68]. This correlates with the observation that the patterns of DNA methylation are consistently abnormal in human cancers; and the expression of tumor suppressor genes (e.g. the cell cycle inhibitor p16) may be reduced due to promoter methylation in some cancers $[68,69]$. Hypermethylation of $\mathrm{CpG}$ dinucleotide islands within gene promoters correlates strongly with transcriptional silencing of gene expression [69].

Epigenetic silencing of gene expression may contribute to the development of breast cancer. Thus, BRCA1 expression is frequently decreased or absent in sporadic breast and ovarian cancers [70-72]; and a subset of these cancers exhibit hypermethylation of the BRCA1 gene promoter on CpG islands $[73,74]$. In addition, some hormone receptor-negative breast cancers exhibit hypermethylation of the ER- $\alpha$ and/or PR promoters. Thus, about $25 \%$ of primary ER- $\alpha$-negative breast cancers and about $40 \%$ of primary PR-negative cancers exhibit hypermethylation of the ER- $\alpha$ and PR promoters, respectively; whereas very few ER- $\alpha / P R$-positive cancers showed methylation of these sites [75,76]. About $80 \%$ of BRCA1 mutant breast cancers are ER- $\alpha$ and PR negative; and a subset of these cancers exhibit hypermethylation of the ER- $\alpha$ promoter [77]. In this regard, dysregulation of expression of DNMT1 has been linked to loss of ER- $\alpha$ expression in ER- $\alpha$-negative breast cancer cells [78]. Interestingly, a recent study indicates that antisense inhibition of DNMT1 causes conversion of ER- $\alpha$-negative human breast cancer cells to ER- $\alpha$ positivity [79]. On the basis of these considerations, it has been suggested that inhibition of DNMT1 and HDAC inhibitors may be a useful therapeutic strategy for breast cancer [79]. It is, as yet, unclear if hypermethylation of the ER- $\alpha$ promoter is a primary event in the development of ER- $\alpha$-negative breast cancer or if hypermethylation occurs following other mechanisms of transcriptional inhibition.

Methylation of the ER- $\alpha$ gene has been observed in a variety of other cancer types [68]. In an interesting study of colon cancer, hypermethylation of the ER- $\alpha$ promoter was observed in colon carcinoma cells, precancerous adenomatous polyps, and the normal colonic mucosa [80]. The incidence of $E R-\alpha$ promoter methylation appeared to be age related; and it increased sharply after age 50. In the same study, expression of exogenous ER- $\alpha$ inhibited the growth of colon cancer cell lines [80]. The authors proposed that hypermethylation of the ER- $\alpha$ gene is an agerelated phenomenon; and colon cancer growth selects for hypermethylation because ER- $\alpha$ inhibits cancer growth.

As noted above, methylation of the PR promoter is also a common event in human breast cancers. The $\mathrm{PR}$ is a major transcriptional target of ER- $\alpha$. Treatment of ER- $\alpha / P R-n e g a t i v e ~ M D A-M B-231$ breast cancer cells with a methylation inhibitor (5-azacytidine) lead to the re-expression of both ER- $\alpha$ and PR [81]. In this study, an anti-estrogen-blocked PR expression, while PR expression could be induced by the estrogenactivated ER- $\alpha$ without demethylation, suggesting that ER- $\alpha$ could overcome the repression of PR expression even in the presence of a methylated PR gene promoter. A final point of interest is the observation that chronic exposure of ER- $\alpha$ breast cancer cells to adriamycin (doxorubicin) caused their conversion to ER- $\alpha$-negative status; and those ER- $\alpha$-negative cells exhibited hypermethylation of the ER- $\alpha$ promoter [82]. These findings raise the possibility that adriamycin might promote hormone insensitivity by inducing the loss of ER- $\alpha$ expression.

\section{Dietary factors}

This section will not attempt to be comprehensive but will review a few of the dietary factors that can influence ER- $\alpha$ signaling. The relationship between obesity and breast cancer has been researched extensively and is reviewed elsewhere [83]. Obesity at menarche and during the post-menopausal years, as quantified by an increased body mass index (BMI), has been shown to increase the risk for breast cancer in the post-menopausal years. While increased endogenous estrogens derived from adipose tissue may be a contributory factor, the mechanism(s) underlying the increased breast cancer risk are probably considerably more complex [83].

Epidemiologic studies suggest that while a diet rich in total vegetables does not affect breast cancer risk, a diet rich in cruciferous vegetables (e.g. cabbage, cauliflower, and broccoli) confers a reduced risk for breast cancer [84,85]. Indole-3-carbinol (I3C), a micronutrient derived from glucobrassein, a component of cruciferous vegetables, has been found to exhibit anti-estrogenic properties and to prevent mammary carcinogenesis and other estrogen-responsive cancer types in experimental mouse and rat models [86-88]. One potential mechanism of action of I3C is through an alteration in hepatic microsomal metabolism of estrogen $[86,89]$. Thus, I3C stimulates 
2-hydroxylation of estrone (E1) at the expense of $16 \alpha$-hydroxylation, resulting in increased production of 2-OH-E1 and decreased production of $16-\mathrm{OH}-\mathrm{E} 1$, a potential carcinogen. I3C causes an increase in the ratio of urinary $2-\mathrm{OH}-\mathrm{E} 1$ to $16-\mathrm{OH}-\mathrm{E} 1$ in humans at well-tolerated doses [90-92], suggesting that it may be an attractive as a breast cancer chemoprevention agent. $\mathrm{I} 3 \mathrm{C}$ exerts other actions that may contribute to its anti-estrogenic actions. Thus, I3C can bind to ER- $\alpha$ and inhibit E2-stimulated ER- $\alpha$ transcriptional activity $[93,94]$. The ability of I3C to inhibit E2-stimulated ER- $\alpha$ activity may be due, in part, to its ability to upregulate BRCA1 expression [94,95]. Finally, I3C and its major active metabolite diindolylmethane (DIM) also mediate E2-independent actions that may contribute to its anti-carcinogenic activity, including upregulation of expression of tumor suppressor genes ([BRCA1, BRCA2, GADD45 $\alpha$ (growth and DNA damage inducible $45 \alpha$ ), E-cadherin, and PTEN (phosphatase and tensin homolog/mutated in multiple advanced cancers 1)) and decreased expression of cyclin-dependent kinase 6 , among other activities [94-99].

Genistein is the major isoflavone derived from soy and is classified as a phytoestrogen. A high intake of soy contributes to the decreased incidence of breast cancer and prostate cancer in Asian women and men, respectively [100]. A recent meta-analysis suggests that increased intake of genistein contributes to a reduced breast cancer risk in pre-menopausal women [101]. One possible explanation is that genistein is a weak estrogen that stimulates ER- $\alpha$ activity in the absence of E2 but inhibits E2-stimulated ER- $\alpha$ activity [102]. Alternatively, genistein exhibits a higher affinity for ER- $\beta$ than for ER- $\alpha$ [103], and its effect on breast cancer risk could be mediated through ER - $\beta$. In this regard, genistein mediates differential coactivator recruitment for ER- $\alpha$ vs. ER- $\beta$ [104]. Genistein can also bind to and activate $A R$, suggesting it is also a phytoandrogen [105]. Genistein exhibits a variety of hormone-independent actions, including inhibition of cell proliferation, but these actions are usually observed at pharmacologic $(>10 \mu \mathrm{M})$ rather than physiologic concentrations.

Lignans (enterodiol and enterolactone) are phytoestrogens derived from flaxseed through the action of bacteria in the colon on their precursor molecules. These compounds may protect against the development of pre-menopausal breast cancer $[106,107]$. Proposed mechanisms of action include inhibition of E2-stimulated ER- $\alpha$ mediated cell proliferation, stimulation of ER- $\beta$ activity, induction of the expression of sex-hormone-binding globulin (SHBG), and an antioxidant activity [106]. Finally, alcohol (ethanol), while not a 'dietary' factor in the nutritional sense can modulate the risk for breast cancer. Thus, it has been established that moderate levels of alcohol consumption increase the risk for post-menopausal breast cancer, particular in collaboration with exogenous estrogens [108]. While the mechanism by which alcohol increases breast cancer risk are uncertain, a recent study indicates that ethanol increases ER- $\alpha$ expression and E2-stimulated ER- $\alpha$ transcriptional activity in cultured ER- $\alpha$-positive human breast cancer cells [109]. The fold-stimulation of ER- $\alpha$ transcriptional activity was significantly greater than that of ER- $\alpha$ protein levels, suggesting that ethanol stimulates the intrinsic ER- $\alpha$ activity. This may be due in part to BRCA1, since ethanol caused corresponding decreases in the expression levels of BRCA1.

\section{Conclusions}

We have reviewed various mechanisms by which $E R-\alpha$ signaling can be inhibited, including transcriptional repression mediated by corepressors and BRCA1; inhibition of ER- $\alpha$ activity by SERMs; inhibition of ER- $\alpha$ production via aromatization; transcriptional silencing of the ER- $\alpha$ gene; heterodimerization with ER- $\beta$; and dietary agents that regulate ER- $\alpha$ signaling by various mechanisms (see Fig. 1). Where appropriate the clinical implications of these mechanisms have been discussed. None of the agents currently utilized to inhibit ER- $\alpha$ signaling are 100\% effective. Thus, recurrences are observed after the use of Tamoxifen or aromatase inhibitors in the adjuvant setting for breast cancer; and neither Tamoxifen nor Raloxifene prevent the development of ER- $\alpha$-negative breast cancers. And ER- $\alpha$-positive cancers may develop resistance to hormonal manipulations or recur as ER- $\alpha$-negative cancers [110]. Finally, existing therapeutic chemoprevention agents have side effects due to pro-estrogenic or anti-estrogenic activities in

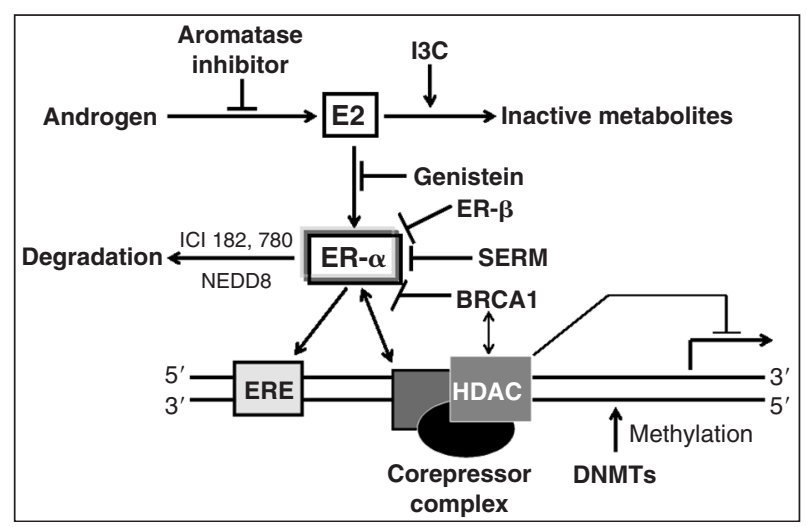

Figure 1.

Schematic diagram illustrating some of the pathways of inhibition of ER- $\alpha$ signaling. See text for definition of abbreviations. 
different tissues. These considerations indicate that although much progress has been made, further research is required to develop better strategies to inhibit ER- $\alpha$ signaling in breast cancer cells and avoid the adverse consequences of ER- $\alpha$ inhibition and/or stimulation in extra-mammary sites.

\section{Acknowledgements}

Dr. E. M. Rosen has been supported, in part, by grants from the United States Public Health Service (RO1-CA82599, RO1-CA80000, and RO1-ES09169) and by a grant from the Susan G. Komen Breast Cancer Foundation (BCTR0201295).

\section{References}

1. Mosselman S, Polman J, Dijkema R. ER-beta: identification and characterization of a novel human estrogen receptor. FEBS Lett 1996; 392: 49-53.

2. Horard B, Vanacker JM. Estrogen receptor-related receptors: orphan receptors desperately seeking a ligand. $J$ Mol Endocrinol 2003; 31: 349-357.

3. Webb P, Nguyen P, Shinsako J, Anderson C, et al. Estrogen receptor activation function 1 works by binding $\mathrm{p} 160$ coactivator proteins. Mol Endocrinol 1998; 12: 1605-1618.

4. Schwabe JW, Neuhaus D, Rhodes D. Solution structure of the DNA-binding domain of the oestrogen receptor. Nature 1990; 348: 458-461.

5. Mclnerney EM, Tsai MJ, O'Malley BW, Katzenellenbogen BS. Analysis of estrogen receptor transcriptional enhancement by a nuclear hormone receptor coactivator. Proc Natl Acad Sci USA 1996; 93: 10069-10073.

6. Sathya G, Yi P, Bhagat S, Bambara RA, et al. Structural regions of ERalpha critical for synergistic transcriptional responses contain co-factor interacting surfaces. Mol Cell Endocrinol 2002; 192: 171-185.

7. Wormke M, Stoner M, Saville B, Walker K, et al. The aryl hydrocarbon receptor mediates degradation of estrogen receptor alpha through activation of proteasomes. Mol Cell Biol 2003; 23: 1843-1855.

8. Xu L, Glass CK, Rosenfeld MG. Coactivator and corepressor complexes in nuclear receptor function. Curr Opin Genet Dev 1999; 9: 140-147.

9. Dobrzycka KM, Townson SM, Jiang S, Oesterreich S. Estrogen receptor corepressors - a role in human breast cancer? Endocr Relat Cancer 2003; 10: 517-536.

10. Renoir JM, Radanyi C, Faber LE, Baulieu EE. The nonDNA-binding heterooligomeric form of mammalian steroid hormone receptors contains a hsp90-bound 59-kilodalton protein. J Biol Chem 1990; 265: 10740-10745.

11. Mclnerney EM, Rose DW, Flynn SE, Westin S, et al. Determinants of coactivator LXXLL motif specificity in nuclear receptor transcriptional activation. Genes Dev 1998; 12: 3357-3368.

12. Hu X, Lazar MA. The CoRNR motif controls the recruitment of corepressors by nuclear hormone receptors. Nature 1999; 402: 93-96.

13. Perissi V, Staszewski LM, Mclnerney EM, Kurokawa R, et al. Molecular determinants of nuclear receptor-corepressor interaction. Genes Dev 1999; 13: 3198-3208.
14. Miki Y, Swensen J, Shattuck-Eidens D, et al. A strong candidate for the breast and ovarian cancer susceptibility gene BRCA1. Science 1994; 266: 66-71.

15. Rosen EM, Fan S, Pestell RG, Goldberg ID. BRCA1 gene in breast cancer. J Cell Physiol 2003; 196: 19-41.

16. Thompson D, Easton DF; Breast Cancer Linkage Consortium. Cancer incidence in BRCA1 mutation carriers. J Natl Cancer Inst 2002; 94: 1358-1365.

17. Fan S, Wang J-A, Meng Q, Yuan R-Q, Ma YX, Erdos MR, Pestell RG, Yuan F, Auborn KJ, Goldberg ID, Rosen EM. BRCA1 inhibits estrogen receptor signaling in transfected cells. Science 1999; 284: 1354-1356.

18. Fan S, Wang JA, Ma YX, Yuan R-Q, et al. p300 modulates BRCA1 inhibits of estrogen receptor activity. Cancer Res 2002; 62: 141-151.

19. Fan S, Wang J-A, Ma YX, Yuan R-Q, et al. Role of direct interaction in BRCA1 inhibition of estrogen receptor activity. Oncogene 2001; 20: 77-87.

20. Ma YX, Tomita $Y$, Fan S, Wu K, Tong $Y$, et al. Structural determinants of the BRCA1: estrogen receptor interaction. Oncogene 2005. [Epublished ahead of print].

21. Zheng L, Annab LA, Afshari CA, Lee WH, Boyer TG. BRCA1 mediates ligand-independent transcriptional repression of the estrogen receptor. Proc Natl Acad Sci USA 2001; 98: 9587-9592.

22. Levin ER. Cellular functions of plasma membrane estrogen receptors. Steroids 2002; 67: 471-475.

23. Razandi M, Pedram A, Rosen EM, Levin ER. BRCA1 inhibits membrane estrogen and growth factor receptor signaling to cell proliferation in breast cancer. $\mathrm{Mol}$ Cell Biol 2004; 24: 5900-5913.

24. Howell SJ, Johnston SR, Howell A. The use of selective estrogen receptor modulators and selective estrogen receptor down-regulators in breast cancer. Best Pract Res Clin Endocrinol Metab 2004; 18: 47-66.

25. Bryant HU, Dere WH. Selective estrogen receptor modulators: an alternative to hormone replacement therapy. Proc Soc Exp Biol Med 1998; 217: 45-52.

26. Wolmark N, Dunn BK. The role of tamoxifen in breast cancer prevention: issues sparked by the NSABP Breast Cancer Prevention Trial (P-1). Ann NY Acad Sci 2001; 949: 99-108.

27. Shiau AK, Barstad D, Loria PM, Cheng L, et al. The structural basis of estrogen receptor/coactivator recognition and the antagonism of this interaction by tamoxifen. Cell 1998; 95: 927-937.

28. Dobrzycka KM, Townson SM, Jiang S, Oesterreich S. Estrogen receptor corepressors - a role in human breast cancer? Endocr Relat Cancer 2003; 10: 517-536.

29. Sakamoto T, Eguchi $H$, Omoto $Y$, Ayabe T, Mori $H$, Hayashi S. Estrogen receptor-mediated effects of tamoxifen on human endometrial cancer cells. Mol Cell Endocrinol 2002; 192: 93-104.

30. Zhang H, McElrath T, Tong W, Pollard JW. The molecular basis of tamoxifen induction of mouse uterine epithelial cell proliferation. J Endocrinol 2005; 184: 129-140.

31. Mclnerney EM, Katzenellenbogen BS. Different regions in activation function-1 of the human estrogen receptor required for antiestrogen- and estradiol-dependent transcription activation. $\mathrm{J}$ Biol Chem 1996; 271: 24172-24178.

32. Webb P, Nguyen P, Kushner PJ. Differential SERM effects on corepressor binding dictate ERalpha activity in vivo. J Biol Chem 2003; 278: 6912-6920. 
33. Fowler AM, Solodin N, Preisler-Mashek MT, Zhang P, Lee AV, Alarid ET. Increases in estrogen receptor-alpha concentration in breast cancer cells promote serine 118/ 104/106-independent AF-1 transactivation and growth in the absence of estrogen. FASEB J 2004; 18: 81-93.

34. Campbell RA, Bhat-Nakshatri P, Patel NM, Constantinidou D, Ali S, Nakshatri H. Phosphatidylinositol 3-kinase/AKT-mediated activation of estrogen receptor alpha: a new model for anti-estrogen resistance. J Biol Chem 2001; 276: 9817-9824.

35. Rogatsky I, Trowbridge JM, Garabedian MJ. Potentiation of human estrogen receptor alpha transcriptional activation through phosphorylation of serines 104 and 106 by the cyclin A-CDK2 complex. J Biol Chem 1999; 274: 22296-22302.

36. Webb P, Nguyen P, Shinsako J, Anderson C, et al. Estrogen receptor activation function 1 works by binding $\mathrm{p} 160$ coactivator proteins. Mol Endocrinol 1998; 12: 1605-1618.

37. Bunone G, Briand PA, Miksicek RJ, Picard D. Activation of the unliganded estrogen receptor by EGF involves the MAP kinase pathway and direct phosphorylation. EMBO $J$ 1996; 15: 2174-2183.

38. Heldring N, Nilsson M, Buehrer B, Treuter E, Gustafsson JA. Identification of tamoxifen-induced coregulator interaction surfaces within the ligand-binding domain of estrogen receptors. Mol Cell Biol 2004; 24: 3445-3459.

39. Thiebaud D, Secrest RJ. Selective estrogen receptor modulators: mechanism of action and clinical experience. Focus on raloxifene. Reprod Fertil Dev 2001; 13: 331-336.

40. Barrett-Connor E, Cauley JA, Kulkarni PM, Sashegyi A, Cox DA, Geiger MJ. Risk-benefit profile for raloxifene: 4-year data From the Multiple Outcomes of Raloxifene Evaluation (MORE) randomized trial. J Bone Miner Res 2004; 19: 1270-1275.

41. Dickler MN, Norton L. The MORE trial: multiple outcomes for raloxifene evaluation - breast cancer as a secondary end point: implications for prevention. Ann NY Acad Sci 2001; 949: 134-142.

42. Martino S, Cauley JA, Barrett-Connor E, Powles TJ, et al. CORE Investigators. Continuing outcomes relevant to Evista: breast cancer incidence in postmenopausal osteoporotic women in a randomized trial of raloxifene. J Natl Cancer Inst 2004; 96: 1751-1761.

43. Parker MG. Action of 'pure' antiestrogens in inhibiting estrogen receptor action. Breast Cancer Res Treat 1993; 26:131-137.

44. Fan M, Bigsby RM, Nephew KP. The NEDD8 pathway is required for proteasome-mediated degradation of human estrogen receptor (ER)-alpha and essential for the antiproliferative activity of $\mathrm{ICI} 182,780$ in ERalpha-positive breast cancer cells. Mol Endocrinol 2003; 17: 356-365.

45. Buzdar AU. Fulvestrant: a new type of estrogen receptor antagonist for the treatment of advanced breast cancer. Drugs Today (Barc) 2004; 40: 751-764.

46. Franco S, Perez A, Tan-Chiu E, Frankel C, Vogel CL. Response to fulvestrant in heavily pretreated postmenopausal women: a single-center experience. Breast Cancer Res Treat 2004; 88: 103-108.

47. Buzdar AU. Aromatase inhibitors in breast cancer. Breast Cancer Online 2001; 4(4).

48. Cora EM, Maihle NJ. Aromatization of breast cancer. Breast Cancer Online 2002; 2(2).
49. Simpson ER, Dowsett M. Aromatase and its inhibitors: significance for breast cancer therapy. Recent Prog Horm Res 2002; 57: 317-338.

50. Corbin CJ, Graham-Lorence S, McPhaul M, Mason JI, Mendelson CR, Simpson ER. Isolation of a full-length cDNA insert encoding human aromatase system cytochrome P-450 and its expression in nonsteroidogenic cells. Proc Nat Acad Sci USA 1988; 85: 8948-8952.

51. Deslypere JP, Verdonck L, Vermeulen A. Fat tissue: a steroid reservoir and site of steroid metabolism. J Clin Endocr Metab 1985; 61: 564-570.

52. Speirs V, Adams IP, Walton DS, Atkin SL. Identification of wild-type and exon 5 deletion variants of estrogen receptor beta in normal human mammary gland. J Clin Endocr Metab 2000; 85: 1601-1605.

53. Weihua Z, Saji S, Makinen S, Cheng G, et al. Estrogen receptor (ER) beta, a modulator of ER alpha in the uterus. Proc Natl Acad Sci USA 2000; 97: 5936-5941.

54. Jisa E, Jungbauer A. Kinetic analysis of estrogen receptor homo- and heterodimerization in vitro. J Steroid Biochem Mol Biol 2003; 84: 141-148.

55. Pettersson K, Delaunay F, Gustafsson JA. Estrogen receptor beta acts as a dominant regulator of estrogen signaling. Oncogene 2000; 19: 4970-4978.

56. Buteau-Lozano H, Ancelin M, Lardeux B, Milanini J, PerrotApplanat M. Transcriptional regulation of vascular endothelial growth factor by estradiol and tamoxifen in breast cancer cells: a complex interplay between estrogen receptors alpha and beta. Cancer Res 2002; 62: 4977-4984.

57. Hall JM, McDonnell DP. The estrogen receptor beta-isoform (ERbeta) of the human estrogen receptor modulates ERalpha transcriptional activity and is a key regulator of the cellular response to estrogens and antiestrogens. Endocrinology 1999; 140: 5566-5578.

58. Li X, Huang J, Yi P, Bambara RA, Hilf R, Muyan M. Single-chain estrogen receptors (ERs) reveal that the ERalpha/beta heterodimer emulates functions of the ERalpha dimer in genomic estrogen signaling pathways. Mol Cell Biol 2004; 24: 7681-7694.

59. Palmieri C, Saji S, Sakaguchi H, Cheng G, et al. The expression of oestrogen receptor (ER)-beta and its variants, but not ERalpha, in adult human mammary fibroblasts. J Mol Endocrinol 2004; 33: 35-50.

60. Holliday R. The inheritance of epigenetic defects. Science 1987; 238: 163-170.

61. Szyf M. The DNA methylation machinery as a target for anticancer therapy. Pharmacol Ther 1996; 70: 1-37.

62. Baylin SB. Tying it all together: epigenetics, genetics, cell cycle, and cancer. Science 1997; 277: 1948-1949.

63. Reale A, Lindsay $H$, Saluz HP, Pradhan S, et al. DNA binding and methyl transfer catalysed by mouse DNA methyltransferase. Biochem J 1995; 312: 855-861.

64. Xie S, Wang Z, Okano M, Nogami M, et al. Cloning, expression and chromosome locations of the human DNMT3 gene family. Gene 1999; 236: 87-95.

65. Jones PL, Veenstra GJ, Wade PA, Vermaak D, et al. Methylated DNA and MeCP2 recruit histone deacetylase to repress transcription. Nat Genet 1998; 19: 187-191.

66. Rountree MR, Bachman KE, Baylin SB. DNMT1 binds HDAC2 and a new co-repressor, DMAP1, to form a complex at replication foci. Nat Genet 2000; 25: 269-277.

67. Bachman KE, Rountree MR, Baylin SB. Dnmt3a and Dnmt3b are transcriptional repressors that exhibit unique 
localization properties to heterochromatin. J Biol Chem 2001; 24: 32282-32287.

68. Berger J, Daxenbichler G. DNA methylation of nuclear receptor genes - possible role in malignancy. $J$ Steroid Biochem Mol Biol 2002; 80: 1-11.

69. Baylin SB, Makos M, Wu JJ, Yen RW, et al. Abnormal patterns of DNA methylation in human neoplasia: potential consequences for tumor progression. Cancer Cells 1991; 3: 383-390.

70. Taylor J, Lymboura M, Pace PE, A'hern RP, et al. An important role for BRCA1 in breast cancer progression is indicated by its loss in a large proportion of non-familial breast cancers. Int J Cancer 1998; 79: 334-342.

71. Wilson CA, Ramos L, Villasenor MR, Anders $\mathrm{KH}$, et al. Localization of human BRCA1 and its loss in high-grade, non-inherited breast carcinomas. Nat Genet 1999; 21: 236-240.

72. Lee WY, Jin YT, Chang TW, Lin PW, Su IJ. Immunolocalization of BRCA1 protein in normal breast tissue and sporadic invasive ductal carcinomas: a correlation with other biological parameters. Histopathology 1999; 34: 106-112.

73. Rice JC, Ozcelik H, Maxeiner P, Andrulis I, Futscher BW. Methylation of the BRCA1 promoter is associated with decreased BRCA1 mRNA levels in clinical breast cancer specimens. Carcinogenesis 2000; 21: 1761-1765.

74. Esteller M, Silva JM, Dominguez G, Bonilla F, et al. Promoter hypermethylation and BRCA1 inactivation in sporadic breast and ovarian tumors. J Natl Cancer Inst 2000; 92: 564-569.

75. Yan L, Yang X, Davidson NE. Role of DNA methylation and histone acetylation in steroid receptor expression in breast cancer. J Mammary Gland Biol Neoplasia 2001; 6: 183-192.

76. Lapidus RG, Ferguson AT, Ottaviano YL, Parl FF, et al. Methylation of estrogen and progesterone receptor gene 5' $\mathrm{CpG}$ islands correlates with lack of estrogen and progesterone receptor gene expression in breast tumors. Clin Cancer Res 1996; 2: 805-810.

77. Archey WB, McEachern KA, Robson M, Offit K, et al. Increased $\mathrm{CpG}$ methylation of the estrogen receptor gene in BRCA1-linked estrogen receptor-negative breast cancers. Oncogene 2002; 21:7034-7041.

78. Nass SJ, Ferguson AT, El-Ashry D, Nelson WG, Davidson NE. Expression of DNA methyl-transferase (DMT) and the cell cycle in human breast cancer cells. Oncogene 1999; 18:7453-7461.

79. Yan L, Nass SJ, Smith D, Nelson WG, Herman JG, Davidson NE. Specific inhibition of DNMT1 by antisense oligonucleotides induces re-expression of estrogen receptor-alpha (ER) in ER-negative human breast cancer cell lines. Cancer Biol Ther 2003; 2: 552-556.

80. Issa JP, Ottaviano YL, Celano P, Hamilton SR, Davidson NE, Baylin SB. Methylation of the oestrogen receptor $\mathrm{CpG}$ island links ageing and neoplasia in human colon. Nat Genet 1994; 7: 536-540.

81. Ferguson AT, Lapidus RG, Davidson NE. Demethylation of the progesterone receptor $\mathrm{CpG}$ island is not required for progesterone receptor gene expression. Oncogene 1998; 17: 577-583.

82. Ottaviano YL, Issa JP, Parl FF, Smith HS, Baylin SB, Davidson NE. Methylation of the estrogen receptor gene $\mathrm{CpG}$ island marks loss of estrogen receptor expression in human breast cancer cells. Cancer Res 1994; 54: 2552-2555
83. Hilakivi-Clarke L, Wang C, Kalil M, Riggins R, Pestell RG. Nutritional modulation of the cell cycle and breast cancer. Endocr Relat Cancer 2004; 11: 603-622.

84. Graham S, Marshall J, Mettlin C, Rzepka T, Nemoto T, Byers T. Diet in the epidemiology of breast cancer. Am J Epidemiol 1982; 116: 68-75.

85. Bradlow HL, Telang NT, Sepkovic DW, Osborne MP. Phytochemicals as modulators of cancer risk. Adv Exp Med Biol 1999; 472: 207-221.

86. Bradlow HL, Michnovicz J, Telang NT, Osborne MP. Effects of dietary indole-3-carbinol on estradiol metabolism and spontaneous mammary tumors in mice. Carcinogenesis 1991; 12: 1571-1574.

87. Kojima T, Tanaka T, Mori H. Chemoprevention of spontaneous endometrial cancer in female donryu rats by indole-3-carbinol. Cancer Res 1994; 54: 1446-1449.

88. Jin L, Qi M, Chen DZ, Anderson A, et al. Indole-3-carbinol prevents cervical cancer in human papilloma virus type 16 (HPV16) transgenic mice. Cancer Res 1999; 59: 3991-3997.

89. Michnovicz JJ, Bradlow HL. Induction of estradiol metabolism by dietary indole-3-carbinol in humans. J Natl Cancer Inst 1990; 82: 947-949.

90. Michnovicz JJ, Adlercreutz H, Bradlow HL. Changes in levels of urinary estrogen metabolites after oral indole3-carbinol treatment in humans. J Natl Cancer Inst 1997; 89: 718-723.

91. Bell MC, Crowley-Nowick P, Bradlow HL, Sepkovic DW, et al. Placebo-controlled trial of indole-3-carbinol in the treatment of CIN. Gynecol Oncol 2000; 78: 123-129.

92. Rosen CA, Woodson GE, Thompson JW, Hengesteg AP, Bradlow HL. Preliminary results of the use of indole-3carbinol for recurrent respiratory papillomatosis. Otolaryngol Head Neck Surg 1998; 118: 810-815.

93. Chen D-Z, Mei Q, Auborn KJ, Carter TH. Indole3-carbinol and diindolylmethane induce apoptosis of human cervical cancer cells and in murine HPV16-transgenic preneoplastic cervical epithelium. J Nutr 2001; 131: 3294-3302.

94. Meng Q, Yuan F, Goldberg ID, Rosen EM, Auborn K, Fan S. Indole-3-carbinol is a negative regulator of estrogen receptor-alpha signaling in human tumor cells. J Nutr 2000; 130: 2927-2931.

95. Carter TH, Liu K, Ralph Jr W, Chen D, et al. Diindolylmethane alters gene expression in human keratinocytes in vitro. J Nutr 2002; 132: 3314-3324.

96. Meng Q, Goldberg ID, Rosen EM, Fan S. Inhibitory effects of indole-3-carbinol on invasion and migration in human breast cancer cells. Breast Cancer Res Treat 2000; 63: 147-152.

97. Meng Q, Mei Q, Chen D-Z, Yuan R, et al. Suppression of breast cancer invasion and migration mediated by indole3-carbinol: associated with up-regulation of BRCA1 and E-cadherin/catenin complexes. J Mol Med 2000; 78: 155-165.

98. Cover CM, Hsieh SJ, Tran SH, Hallden G, et al. Indole-3carbinol inhibits the expression of cyclin-dependent kinase- 6 and induces a G1 cell cycle arrest of human breast cancer cells independent of estrogen receptor signaling. J Biol Chem 1998; 273: 3838-3847.

99. Cover CM, Hsieh SJ, Cram EJ, Hong C, Riby JE, Bjeldanes LF, Firestone GL. Indole-3-carbinol and tamoxifen cooperate to arrest the cell cycle of MCF-7 human breast cancer cells. Cancer Res 1999; 59: 1244-1251. 
100. Wu AH. Soy and risk of hormone-related and other cancers. Adv Exp Med Biol 2001; 492: 19-28.

101. Trock B, Butler W, Clarke R, Hilakivi-Clarke L. Metaanalysis of soy intake and breast cancer risk. J Nutr 2000; 130: 690S-691S.

102. Ratna WN. Inhibition of estrogenic stimulation of gene expression by genistein. Life Sci 2002; 71: 865-877.

103. Kuiper GG, Lemmen JG, Carlsson B, Corton JC, et al. Interaction of estrogenic chemicals and phytoestrogens with estrogen receptor beta. Endocrinology 1998; 139: 4252-4263.

104. Bramlett KS, Wu Y, Burris TP. Ligands specify coactivator nuclear receptor (NR) box affinity for estrogen receptor subtypes. Mol Endocrinol 2001; 15: 909-922.

105. Maggiolini M, Vivacqua A, Carpino A, Bonofiglio D, et al. The mutant androgen receptor T877A mediates the proliferative but not the cytotoxic dose-dependent effects of genistein and quercetin on human LNCaP prostate cancer cells. Mol Pharmacol 2002; 62: 1027-1035.
106. Wang LQ. Mammalian phytoestrogens: enterodiol and enterolactone. J Chromatogr B Analyt Technol Biomed Life Sci 2002; 777: 289-309.

107. McCann SE, Muti P, Vito D, Edge SB, Trevisan M, Freudenheim JL. Dietary lignan intakes and risk of preand postmenopausal breast cancer. Int $J$ Cancer 2004; 111: 440-3.

108. Singletary KW, Gapstur SM. Alcohol and breast cancer: review of epidemiologic and experimental evidence and potential mechanisms. J Am Med Assoc 2001; 286: 2143-2151.

109. Fan S, Meng Q, Gao B, Grossman J, et al. Alcohol stimulates estrogen receptor signaling in human breast cancer cell lines. Cancer Res 2000; 60: 5635-5639.

110. Kuukasjarvi T, Kononen J, Helin H, Holli K, Isola J. Loss of estrogen receptor in recurrent breast cancer is associated with poor response to endocrine therapy. $J$ Clin Oncol 1996; 14: 2584-2589. 